\title{
Tadalafil increases muscle capillary recruitment and forearm glucose uptake in women with type 2 diabetes
}

\author{
P.-A. Jansson • G. Murdolo • L. Sjögren • B. Nyström • \\ M. Sjöstrand $\cdot$ L. Strindberg $\cdot$ P. Lönnroth
}

Received: 7 March 2010 / Accepted: 18 May 2010 / Published online: 10 June 2010

(C) The Author(s) 2010. This article is published with open access at Springerlink.com

\begin{abstract}
Aims/hypothesis Recent evidence suggests that reduced synthesis of nitric oxide in endothelial cells, i.e. endothelial dysfunction, contributes to the impaired action of insulin in the vasculature of patients with type 2 diabetes. We investigated whether selective inhibition of phosphodiesterase- 5 by tadalafil has beneficial effects on peripheral microcirculation and glucose uptake in these patients.

Methods We enrolled seven postmenopausal women with type 2 diabetes and ten age-matched healthy women as controls in a placebo-controlled study to evaluate the acute metabolic effects of tadalafil. We performed microdialysis and blood flow measurements in muscle, and sampled arterial and deep venous blood before and after a single
\end{abstract}

Electronic supplementary material The online version of this article (doi:10.1007/s00125-010-1819-4) contains supplementary material, which is available to authorised users.

P.-A. Jansson $(\bowtie) \cdot$ L. Sjögren · M. Sjöstrand $\cdot$ L. Strindberg •

P. Lönnroth

The Lundberg Laboratory for Diabetes Research,

Center of Excellence for Cardiovascular and Metabolic Research,

Department of Molecular and Clinical Medicine,

Institute of Medicine, Sahlgrenska University Hospital,

University of Gothenburg,

Blå Stråket 5 ,

S-413 45 Göteborg, Sweden

e-mail: per-anders.jansson@medic.gu.se

G. Murdolo

Department of Internal Medicine,

Perugia University,

Perugia, Italy

B. Nyström

Department of Cardiology,

University of Gothenburg,

Gothenburg, Sweden dose of tadalafil $20 \mathrm{mg}$ or placebo. Circulating glucose and insulin levels, muscle capillary recruitment as reflected by permeability surface area for glucose $\left(\mathrm{PS}_{\mathrm{glu}}\right)$ and forearm glucose uptake were measured.

Results In women with type 2 diabetes, but not in the control group, tadalafil induced increases in the incremental AUC for $\mathrm{PS}_{\mathrm{glu}}$ (tadalafil vs placebo $41 \pm 11$ vs $4 \pm 2 \mathrm{ml}$ $\left.[100 \mathrm{~g}]^{-1} \mathrm{~min}^{-1}, p<0.05\right)$ and forearm glucose uptake (46 \pm 9 vs $\left.8 \pm 4 \mu \mathrm{mol}[100 \mathrm{~g}]^{-1} \mathrm{~min}^{-1}, p<0.05\right)$. The variable that best predicted forearm glucose uptake was $\mathrm{PS}_{\mathrm{glu}}$, which explained $70 \%$ of its variance. However, fasting glucose and insulin concentrations were similar following treatment with placebo or tadalafil in the two groups.

Conclusions/interpretation This study suggests that tadalafil evokes positive metabolic effects in insulin-resistant women with type 2 diabetes.

Keywords Glucose-lowering drugs · Endothelial dysfunction · Insulin resistance - Microdialysis .

Phosphodiesterase-5

Abbreviations
$\begin{array}{ll}\triangle \mathrm{AUC} & \text { AUC for the tadalafil vs placebo day } \\ \text { PDE-5 } & \text { Phosphodiesterase-5 } \\ \text { PS }_{\text {glu }} & \text { Permeability surface area for glucose }\end{array}$

\section{Introduction}

Previous studies have shown strong associations between microvascular dysfunction and insulin resistance [1, 2]. Recent evidence suggests that reduced synthesis of nitric oxide in endothelial cells contributes to the impaired action of insulin in the vasculature of patients with insulin 
resistance syndrome [3]. A recent study of the pumpperfused rat hindlimb showed that stimulation of nitric oxide production by methacholine induced positive effects on muscle metabolism [4], while we have previously demonstrated beneficial effects of methacholine on capillary recruitment and forearm glucose uptake in insulin-resistant obese humans [5]. However, as methacholine cannot be used therapeutically, alternative approaches would be required to promote nitric oxide signalling. Nitric oxide promotes vasorelaxation by increasing levels of cyclic guanosine monophosphate, which is degraded by phosphodiesterase 5 (PDE-5). PDE-5 inhibition should thus result in an amplified nitric oxide signal and improved vascular function. However, little is known about the metabolic effects of PDE-5 inhibition in skeletal muscle. Here, we investigated whether the selective PDE-5 inhibitor tadalafil improves muscle capillary recruitment and forearm glucose uptake in postmenopausal women with type 2 diabetes.

\section{Methods}

Study participants This study was conducted on seven postmenopausal women with type 2 diabetes and ten agematched healthy women as controls. Men were not included because of ethical concerns.

The type 2 diabetes women were eligible if they met the following criteria: (1) age 55 to 65 years; (2) BMI 27 to $35 \mathrm{~kg} / \mathrm{m}^{2}$; (3) no tobacco use; (4) $\mathrm{HbA}_{1 \mathrm{c}} 5 \%$ to $7.5 \%$ (reference values $3.9 \%$ to $5.3 \%$ ); (5) no significant complications and concomitant metabolic disease as determined by medical history, physical examination and screening laboratory evaluations; and (6) no ongoing treatment with oestrogens, nitrates, beta-blockers or glucocorticoids.

The healthy controls were enrolled according to the following criteria: (1) a healthy state as determined by medical history, physical examination and screening laboratory evaluations; (2) BMI 18 to $25 \mathrm{~kg} / \mathrm{m}^{2}$; (3) normal glucose tolerance during a $75 \mathrm{~g}$ oral glucose tolerance test; (4) no current use of oestrogen or other regular medications; and (5) no tobacco use.

Clinical characteristics of the participants are shown in Table 1. All participants gave written informed consent and the study protocols were approved by the Ethics Committee at the University of Gothenburg, Sweden.

Study procedures After an overnight fast, the investigation started at 08:00 hours with participants lying supine in a room kept at $27^{\circ} \mathrm{C}$. The type 2 diabetes women did not take their usual medication (except insulin) the evening before and on the morning of the study day. Catheters were inserted into a deep antecubital vein of the right forearm
Table 1 Clinical characteristics of women participants

\begin{tabular}{|c|c|c|c|}
\hline & Control & Type 2 diabetes & $p$ value \\
\hline$n$ & 10 & 7 & \\
\hline Age (years) & $60 \pm 5$ & $61 \pm 6$ & NS \\
\hline BMI $\left(\mathrm{kg} / \mathrm{m}^{2}\right)$ & $22.7 \pm 1.0$ & $29.5 \pm 3.4$ & 0.0006 \\
\hline Waist circumference $(\mathrm{cm})$ & $82 \pm 5$ & $100 \pm 12$ & 0.002 \\
\hline Systolic BP (mmHg) & $118 \pm 10$ & $140 \pm 11$ & 0.003 \\
\hline Diastolic BP (mmHg) & $78 \pm 7$ & $87 \pm 5$ & 0.028 \\
\hline $\mathrm{HbA}_{1 \mathrm{c}}(\%)^{\mathrm{a}}$ & $4.4 \pm 0.1$ & $5.5 \pm 0.8$ & 0.0008 \\
\hline Plasma glucose (mmol/l) & $4.7 \pm 0.3$ & $7.0 \pm 1.2$ & 0.0006 \\
\hline Serum insulin (pmol/1) & $30 \pm 8$ & $90 \pm 36$ & 0.0006 \\
\hline
\end{tabular}

Data presented as mean $\pm \mathrm{SD}$

${ }^{\text {a }}$ Reference value $3.9-5.3 \%$

and into the radial artery of the left arm for sampling of deep venous and arterial blood, respectively; a catheter was also inserted into a superficial vein of the left forearm for blood sampling. Thereafter one mercury in-silastic strain gauge was placed on the upper third of the right forearm for blood flow measurements by plethysmography [5]. Muscle microdialysis for interstitial measurements of glucose was performed as previously described [6]. Calibration of the catheters was performed using urea as an internal reference.

Study protocol The study participants received either placebo or $20 \mathrm{mg}$ tadalafil orally on one occasion and the opposite treatment after an interval of 4 to 6 weeks. From $1 \mathrm{~h}$ before tadalafil or placebo until $4 \mathrm{~h}$ after treatment measurements were taken every $15 \mathrm{~min}$ (muscle dialysates) or 30 min (blood flow and blood sampling). Baseline was defined as the mean of the measurements taken in the $1 \mathrm{~h}$ before administration of tadalafil or placebo. Samples collected were immediately stored at $-20^{\circ} \mathrm{C}$ until analysed.

Calculations We used substrate balance studies and the equations of Fick and Renkin to estimate muscle glucose uptake and capillary recruitment in response to tadalafil in the fasting state $[6,7]$. Permeability surface area for glucose $\left(\mathrm{PS}_{\mathrm{glu}}\right)$ was calculated as described previously [7].

Analytical methods Metabolite concentrations in dialysates and plasma fractions were determined with a colorimetric (glucose) and an ultraviolet (urea) method on a microdialysis analyser (CMA 600; CMA Microdialysis, Stockholm, Sweden). Serum insulin concentrations were measured by an ultrasensitive insulin ELISA (Mercodia, Uppsala, Sweden) with a detection limit of $0.4 \mathrm{pmol} / 1$ and intra-and interassay coefficients of variation of $5.3 \%$ and $2.7 \%$, respectively. 
Statistical analysis Comparisons within and between the groups were performed using two-way ANOVA for repeated measures. AUC and incremental AUC were calculated by the trapezoidal integration method. The correlation between pairs of variables was assessed by a simple linear regression analysis, while multivariate relationships were analysed using a general linear model. Data are shown as mean \pm SEM. A two-sided $p$ value of $p<0.05$ was considered statistically significant. Statistical analyses were carried out using software from StatView (Abacus Concepts, Berkeley, CA, USA) and SAS Institute (Cary, NC, USA).

\section{Results}

Compared with placebo, tadalafil did not affect the incremental AUC for either $\mathrm{PS}_{\mathrm{glu}}$ or forearm glucose uptake in the control group, but did promote increases in both of these measurements in the type 2 diabetic women (Fig. 1a-d). Tadalafil did not affect the incremental AUC for forearm blood flow in any of the study groups (Fig. 1e-f).

The difference in AUC for the tadalafil vs placebo day ( $\triangle \mathrm{AUC}$ ) for $\mathrm{PS}_{\mathrm{glu}}$ correlated with $\triangle \mathrm{AUC}$ for forearm glucose uptake in the control group $\left(r^{2} 0.74, p<0.01\right)$ and in the type 2 diabetic women $\left(r^{2} 0.89, p<0.01\right)$.

Multiple linear regression analysis showed that $\triangle \mathrm{AUC}$ $\mathrm{PS}_{\mathrm{glu}}$ was an independent predictor of forearm glucose uptake and accounted for approximately $70 \%$ of its variance (Electronic supplementary material [ESM] Table 1). Other confounders measured did not substantially modify the prediction by $\triangle \mathrm{AUC} \mathrm{PS}_{\mathrm{glu}}$ alone and only accounted for additional $5 \%$ of variance (ESM Table 1).

No significant differences in serum insulin and plasma glucose levels were shown at baseline, and at 2 and $4 \mathrm{~h}$ following treatment with placebo or tadalafil in both study groups (data not shown).
Fig. 1 Incremental AUC for $\mathrm{PS}_{\text {glu }}(\mathbf{a}, \mathbf{b})$, forearm glucose uptake (c, d) and forearm blood flow $(\mathbf{e}, \mathbf{f})$ in healthy controls $(\mathbf{a}, \mathbf{c}, \mathbf{e})$ and patients with type 2 diabetes $(\mathbf{b}, \mathbf{d}, \mathbf{f})$ following placebo (white circles/bars) or tadalafil $20 \mathrm{mg}$ (black circles/ bars). All negative incremental AUC values were set to zero, leaving means above zero in bar graph insets. ${ }^{*} p<0.05$ compared with placebo a

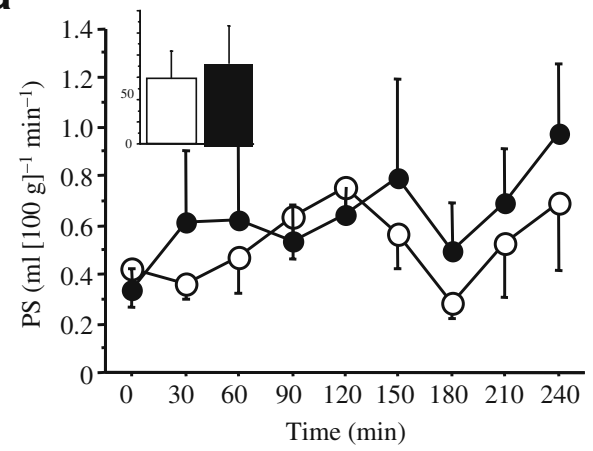

C

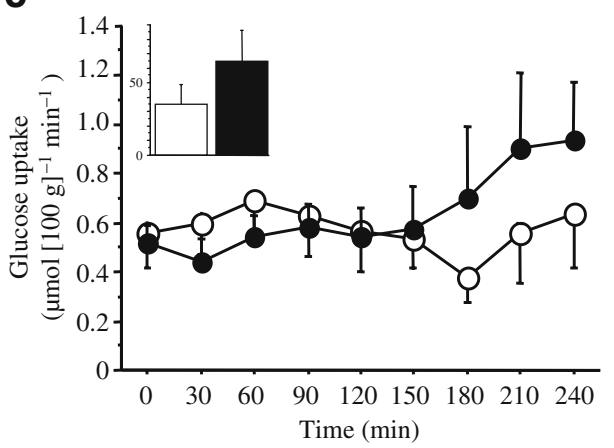

e

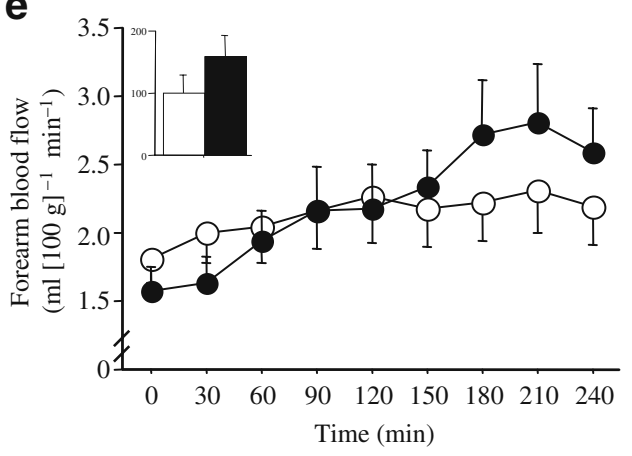

b

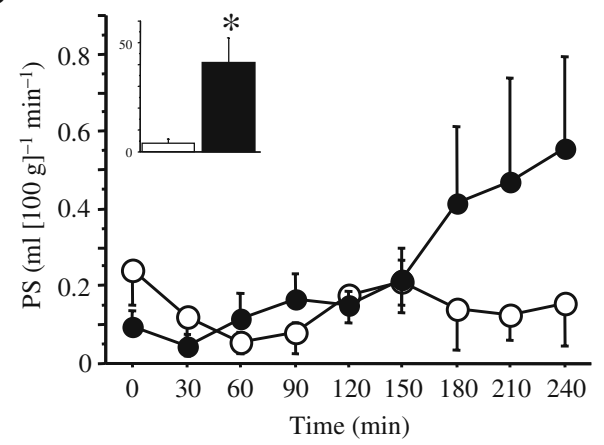

d

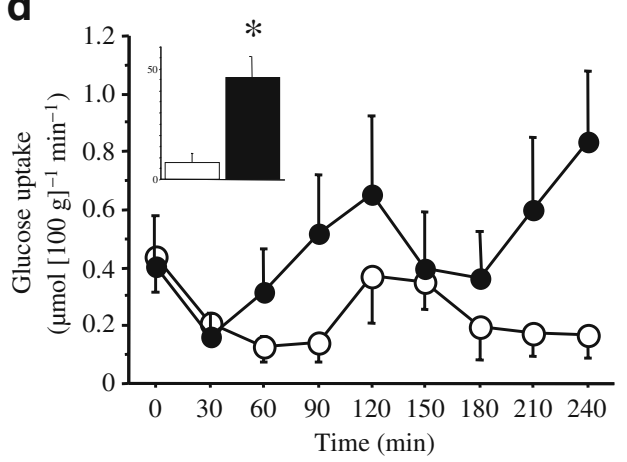

f

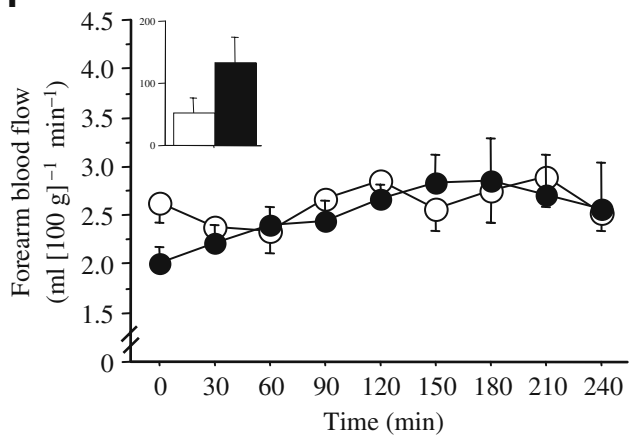




\section{Discussion}

Our evaluation of the potential of PDE-5 inhibition to improve peripheral microcirculation and metabolism in women with type 2 diabetes showed that tadalafil increased capillary recruitment and muscle glucose uptake in the forearm of insulin-resistant humans. Our study is the first to suggest that PDE-5 inhibition may be a novel approach to improve glucose uptake in patients with type 2 diabetes.

Our current findings are in agreement with our previous study, which showed increased capillary surface area and glucose uptake in insulin-resistant obese patients following methacholine infusion [5]. Interestingly, a recent study in high-fat fed mice showed that chronic treatment with the PDE-5 inhibitor sildenafil resulted in increased muscle glucose uptake, but without activation of downstream insulin signalling in the muscle extracts [8]. The authors thus speculated that glucose uptake was facilitated by improved capillary recruitment or by increased cyclic guanosine monophosphate levels in skeletal muscle cells [8]. This could plausibly explain our results, indicating that a component of muscle glucose uptake is independent of $\mathrm{PS}_{\mathrm{glu}}$. In contrast to our findings, a recent study in women with the metabolic syndrome showed an effect of tadalafil on beta cell function, whereas insulin resistance as measured by the minimal model was unchanged [9]. In the absence of this test in the present study, one should consider that positive effects of tadalafil on metabolism may be mediated by effects on insulin secretion, insulin sensitivity or both.

Our observation of a strong correlation between $\triangle \mathrm{AUC}$ $\mathrm{PS}_{\mathrm{glu}}$ and $\triangle \mathrm{AUC}$ forearm glucose uptake in both study groups is consistent with previous studies showing that a microvascular response is critical for glucose uptake in skeletal muscle $[4,10]$. Thus, it is possible that increased nutritive blood flow may enhance glucose delivery to insulin-resistant muscle in the postabsorptive state, too. Our multiple regression analysis showed that forearm blood flow did not substantially affect the variance of forearm glucose uptake. The results are in agreement with the concept that muscle glucose uptake is more dependent on capillary recruitment than on forearm blood flow in type 2 diabetes patients $[6,10]$.

The participants experienced some tadalafil-related side effects such as myalgia, dyspepsia and nausea, but hypotension was not observed. Chronic treatment with low-dose tadalafil is not associated with tachyphylaxis or serious side effects [11], indicating that it is a safe drug to use.

In conclusion, this study implies that tadalafil has acute positive effects on capillary recruitment and glucose uptake in insulin-resistant skeletal muscle of type 2 diabetic women. As we investigated the response to tadalafil in the fasting state, further studies will be required to delineate whether PDE-5 inhibition has beneficial effects on the vasculature and beta cell function after a meal, and on insulin sensitivity assessed by glucose clamp in chronic studies.

Acknowledgements We thank K. Stenlöf at the Clinical Trial Centre for generous support during the study, and S.-E. Ricksten and his colleagues at the Department of Anaesthesiology for catheterisation of radial arteries. This study was supported by an EFSD/Servier Grant Award, LUA/ALF funds, the Swedish Research Council grant K200855X-15358-04-3 and the Swedish Diabetes Association.

Duality of interest M. Sjöstrand is employed by AstraZeneca Research and Development, Sweden. All other authors declare that there is no duality of interest associated with this manuscript.

Open Access This article is distributed under the terms of the Creative Commons Attribution Noncommercial License which permits any noncommercial use, distribution, and reproduction in any medium, provided the original author(s) and source are credited.

\section{References}

1. Jaap AJ, Hammersley MS, Shore AC, Tooke JE (1994) Reduced microvascular hyperaemia in subjects at risk of developing type 2 (non-insulin-dependent) diabetes mellitus. Diabetologia 37: 214-216

2. Caballero AE, Arora S, Saouaf R et al (1999) Microvascular and macrovascular reactivity is reduced in subjects at risk for type 2 diabetes. Diabetes 48:1856-1862

3. Serné EH, de Jongh RT, Eringa EC, Ijzerman RG, de Boer MP, Stehouwer CD (2006) Microvascular dysfunction: causative role in the association between hypertension, insulin resistance and the metabolic syndrome. Essays Biochem 42:163-176

4. Mahajan H, Kolka CM, Newman J, Rattigan S, Richards SM, Clark M (2006) Vascular and metabolic effects of methacholine in relation to insulin action in muscle. Diabetologia 49:713-723

5. Murdolo G, Sjöstrand M, Strindberg L et al (2008) Effects of intrabrachial metacholine infusion on muscle capillary recruitment and forearm glucose uptake during physiological hyperinsulinemia in obese, insulin-resistant individuals. J Clin Endocrinol Metab 93:2764-2773

6. Gudbjörnsdóttir S, Sjöstrand M, Strindberg L, Lönnroth P (2005) Decreased muscle capillary permeability surface area in type 2 diabetic subjects. J Clin Endocrinol Metab 90:1078-1082

7. Crone C, Levitt D (1984) Capillary permeability to small solutes. In: Renkin E, Michel C, Geiger S (eds) Handbook of physiology. The cardiovascular system. Microcirculation. American Physiological Society, Maryland, pp 411-466

8. Ayala J, Bracy D, Julien B, Rottman J, Fueger P, Wasserman D (2007) Chronic treatment with sildenafil improves energy balance and insulin action in high fat-fed conscious mice. Diabetes 56:1025-1033

9. Hill KD, Eckhauser AW, Marney A, Brown NJ (2009) Phosphodiesterase 5 inhibition improves beta cell function in the metabolic syndrome. Diab Care 32:857-859

10. Coggins M, Lindner J, Rattigan S et al (2001) Physiologic hyperinsulinemia enhances human skeletal muscle perfusion by capillary recruitment. Diabetes 50:2682-2690

11. Carson CC, Rajfer J, Eardley I et al (2004) The efficacy and safety of tadalafil: an update. BJU Int 93:1276-1281 